mixture to possess, there would obviously be interference produced by the thermo-electric currents set up owing to the juxtaposition of these masses of unlike metals. It would be particularly interesting to observe whether pure entectic alloys or chemical compounds of metals, which alone appear to form really homogeneous masses of mixed metals, would behave like pure metals, or like other alloys in regard to conductivity at low temperatures.

In order to detect the presence of opposing E.M.F.s, we first tried the experiment of passing a fairly intense current through a bar of alloy, breaking contact by means of a simple switch, and immediately making connection with a galvanometer, the interval of time elapsing between the reversal of connections being but a small fraction of a second. We have hitherto, however, failed to obtain any indication in this manner, a fact which we ascribe to the rapidity with which the temperature of the mass is equalised, owing to the minute size of its constituent particles, and to the appreciable time that must elapse between the break of the current and the contact with the galvanometer. Even when the time was reduced to $\mathrm{I} /$ rooth of a second or less by the use of a Morse key, and when the process was repeated five times a second, no consistent indication of a residual E.M.F. could be detected with a D'Arsonval galvanometer giving a deflection of $0.5 \mathrm{~mm}$. per micro-volt. The ordinary thermoelectric effects had of course to be eliminated, and were very troublesome.

The next experiment was to balance the resistance of two pieces of wire of equal diameter-one of copper, the other of alloy-against each other, using equal ratio arms on a Wheatstone bridge, and then by means of a secohmmeter to try if the resistance of the alloy diminished when the current was rapidly reversed. In all cases there was found to be a distinct reduction of the resistance of the alloy relatively to the copper, the above-mentioned galvanometer giving deflections of from to to I $5 \mathrm{~mm}$., with 60 reversals per second. In one case the alloy was copper $=75$ per cent. : gold $=25$ per cent., the wire being $0.7 \mathrm{~mm}$. in diameter and $820 \mathrm{~mm}$. long, whilst the copper wire was $0.7 \mathrm{~mm}$. in diameter and $4100 \mathrm{~mm}$. long; the current used was about $\mathrm{I} \cdot 5 \mathrm{amp}$., and the resistance of each wire was about $0.18 \mathrm{ohms}$. A deflection of $15 \mathrm{~mm}$. on the galvanometer scale, corresponding to 30 micro-volts, would be caused by an un. balanced E.M.F , in one of the wire $=105$ micro-volts, or, say, $I_{i} / 2600$ th of the total E.M.F.

The time actually occupied in the reversal of the current was estimated as varying between $\mathrm{r} / 500$ th and $\mathrm{r} /$ /oooth of a second, which was the time available for equalisation of temperature before the current was started in the opposite direction. Any residual E.M.F. would then assist the current at "make," and so reduce the apparent resistance. In any case, at the first instant of starting the current, the opposing E.M.F. would be absent, but the time required for its appearance would be very small compared with the time between reversals ( $1 / 60 t h$ of a second). Increased effect should therefore be sought by in. creasing the number of reversals per second rather than by shortening the time between stopping and re-starting the current.

Care was, of course, taken to ensure equal capacities and in ductances in each pair of arms of the bridge; and an experiment was made to see if the observed effect was due to the current in the copper wire becoming concentrated near the surface. A copper wire $1000 \mathrm{~mm}$. long and $0.35 \mathrm{~mm}$. in diameter was balanced against another copper wire $4000 \mathrm{~mm}$. long and $0.7 \mathrm{~mm}$. in diameter; but no variation of resistance was observed. At this point the investigation was allowed to rest, pending the construction of special apparatus and the arrival of the summer vacation. WALTER G. MCMILLAN.

Departments of Metallurgy and of Physics, Robert H. Housman.

Mason College, Birmingham, June 22.

\section{Are Röntgen Rays Polarised?}

Mr. L. Casella has made for me a Crookes' tube having as the anode a platinum window sealed into the end of the tube opposite the kathode, which is the ordinary aluminium disc. Owing to the glass sealing, only a small portion of the platinum, about $3 \mathrm{~mm}$. in diameter, is free to act. The light from all but this portion was screened off by thick glass discs and a bras disc, these having each an aperture in the centre. The result, with the fluorescent screen, was at first poor, because the vacuum was too low; but as that got higher it improved, and I was able to electrograph a part of the hand, by the rays given off by this small platinum window, in 15 seconds, the plate being $2 \frac{1}{2}^{\prime \prime}$ from the window. An ordinary focus tube takes 30 seconds to produce the same effect under similar conditions, but gives better definition. With the platinum window tube, though the bones are defined on the fluorescent screen, there seems to be too much white light, and the difference between bones and flesh is less marked. The tilted platinum of a focus tube, apparently, reflects most of the kathode rays, but transmits some. Compare the behaviour of the platinum in both tubes with the action of light on glass. With both glass and platinum, part of the rays are transmitted and part reflected, the proportion varying with the angle of incidence; but, with both, those rays which are perpendicular are apparently transmitted. If the glass be tilted at the proper angle, the reflected rays and a small part of the transmitted rays are polarised. Suppose the plate of glass in the position of the platinum window, and the source of light a luminous point within the tube; although most of the transmitted light would be radiated direct from the luminous point, part would be rays which had been polarised by refiection from the walls of the tube. The analogy would still hold good, for we know that, as far as X-rays are concerned, glass behaves very similarly to platinum, for these rays are under suitable conditions given off by both.

These considerations and the appearance of microscopic preparations containing bone undecalcified when examined by low powers and ordinary light under Nicol prisms, lead me to hazard the suggestion that a bare possibility exists of X-rays being polarised kathode rays. Were this so, the two kinds of $\mathrm{X}$-ray described by several observers would be explained, and we should also understand why those who have tried to polarise these X-rays should have failed, the rays being already polarised. If this view is correct, extinction of the X-rays should be caused by reflection from a second platinum surface at the proper angle. Whether this would succeed at atmospheric pressure, I know not; the experiment should be tried in vacuo, and a tube con structed specially for the purpose. The window tube has, at all events, proved that a quantity of kathode rays, with some $\mathrm{X}$-rays, may be transmitted through moderately thin platinum. under these conditions. J. Willian GifFord.

Chard, June 9.

\section{A Curious Bird's Nest.}

A CURIOUs bird's nest, or rather its adjuncts, has lately been presented to the Warwick Museum. It was found in a curved iron pipe intended to deliver water from a well at the baths, and appears not to have been used for some time. The entire length of the pipe was four feet, and the diameter five inches. The bird had built its nest in the centre, and had not only surrounded it with moss and other materials, but had extended them for some length on each side, the total amounting to two feet two inches. The singular thing is that the bird should have taken so much trouble to do this, and it really might seem as if, like the bower birds, it had done it in sport; for it was not necessary (though the sharp little bird may have thought so) for the preservation of the nest to extend it so far on each side with moss, feathers, and other things. The eight small eggs in the nest appear to have belonged to the blue titmouse.

$$
\text { June } 22 . \quad \text { P. B. Brodie. }
$$

\section{"Hydrodictyon reticulatum."}

IT may interest readers of NATURE who collect fresh-water Algæ, to know how easy of cultivation is this beautiful species It occurs frequently, though by no means every year, in one of the tanks in the Royal Gardens, Kew. Last summer, about this time, I gathered it there in considerable quantities. After preparing specimens for demonstration, I placed the remainder in a glass dish, where it remained in my study, entirely neglected, except for an occasional renewal of the water, until a week or two ago, when I found it still in beautiful condition, with both large and small nets. It is to be found again this year in its original habitat, with nets of an unusually large, almost gigantic, size.

London, June 2o,

No. I39I, VOL. 54] 